\title{
Development of Negative-type Photosensitive Polyimide, Based on Poly(amic acid)s, Photo Base Generator and Thermal Base Generator
}

\author{
Tomohito Ogura, Katsuhisa Mizoguchi, and Mitsuru Ueda* \\ Department of Organic and Polymeric Materials, Graduate School of Science and Engineering, \\ Tokyo Institute of Technology, 2-12-1, O-okayama, H-120, Meguro-ku, Tokyo 152-8552, Japan \\ ueda.m.ad@m.titech.ac.jp
}

A negative-type photosensitive polyimide (PSPI) based on poly(amic acid) (PAA), a photo base generator (PBG), \{[(4,5-dimethoxy-2-nitrobenzyl) oxy]carbonyl 2,6-dimethyl piperidine (DNCDP) and a thermal base generator (TBG), $N$-(p-nitrophenyl)-2,6-dimethylpiperidine (NDP) has been developed. The PAA was prepared from 3,3',4,4'-biphenyltetracarboxylic dianhydride (BPDA) and 3,3'-sulfonyldianiline (SDA) in N,N-dimethylacetamide (DMAc) and used directly for lithographic evaluations. The TBG was easily prepared by the reaction of $p$-nitrophenyl chloroformate with 2,6-dimethylpiperidine. The PAA film containing $10 \mathrm{wt} \% \mathrm{NDP}$ was converted the polyimide (PI) at $200{ }^{\circ} \mathrm{C}$. The PSPI consisting of PAA (83 wt \%), PBG (8.5 wt \%) and TBG (8.5 wt \%) exhibited a high sensitivity $\left(\mathrm{D}_{0.5}\right)$ of $38 \mathrm{~mJ} / \mathrm{cm}^{2}$ and a contrast $\left(\gamma_{0.5}\right)$ of 0.56 when it was exposed to a $365 \mathrm{~nm}$ line (i-line), post-baked at $170{ }^{\circ} \mathrm{C}$ for $2 \mathrm{~min}$, and developed with $2.38 \mathrm{wt} \%$ TMAHaq. A clear negative image of $8 \mu \mathrm{m}$ line and space pattern was printed in a film which was exposed to $500 \mathrm{~mJ} / \mathrm{cm}^{2}$ of $i$-line by contact printing mode, fully converted to the corresponding PI pattern upon heating at $200^{\circ} \mathrm{C}$, and confirmed by SEM and FTIR spectroscopy.

Keywords: polyimides / photosensitive polymer / photobase generator/

thermal base generator

\section{Introduction}

Photosensitive polyimides (PSPIs) [1-5] are used as buffer coatings to protect bare chips from stresses induced by fillers or thermal mismatches between a passivation layer and molding materials. PSPIs possess high mechanical strength, thermal stability, and low dielectric constants. Most of the negative-type PSPIs are prepared from poly(amic acids) (PAAs), where cross-linking sites are introduced to PAAs through ester [1-2], acid amine ion interactions [3] or direct attachment to the aromatic rings in PAAs [4]. Moreover the chemically amplified PSPIs using cross-linkers were developed [5-6]. Finally, the patterns of PAAs are converted to those of the corresponding polyimides (PIs) by high temperature thermal treatment. Recently, the thermally unstable components and the thinner silicone wafers for stacking silicone chips have been begun to use in microelectronic devices. Therefore, these materials are very difficult to use because of thermal decomposition and thermal stress. To remedy these problems, a low temperature imidization is required in industry. In a previous paper, we reported a direct formulation of PSPI based on an aromatic PAA and a photobase generator (PBG) [7]. This patterning process also provides a lowtemperature imidization lower than $200{ }^{\circ} \mathrm{C}$. However, a large amount of PBG is required to carry out the low-temperature imidization. On the other hand, we also reported several carbamate derivatives as a TBG that enhances both storage stability and processability of PAA 
solutions because of non-reactivity at storage temperatures, while the cyclization of PAA is promoted within a specific range of elevated temperatures [8].

In this study, we report an alkalinedevelopable, chemically amplified negative-type PSPI based on a PAA, a PBG, \{[(4,5-dimethoxy2-nitrobenzyl)oxy]carbonyl 2,6-dimethyl

piperidine (DNCDP) and a TBG, $N-(p-$ nitrophenyl)-2,6-dimethylpiperidine (NDP) that provides a high sensitive and low temperature curable PSPI. An amount of PBG is decreased by using a high transparent PAA at $365 \mathrm{~nm}$. Decomposition of NDP will be promoted by the base generated from the PBG, and the generated base from NDP will act as a catalyst for the low temperature imidization. This patterning process and the subsequent low-temperature cyclization using PSPI are shown in Scheme 1.

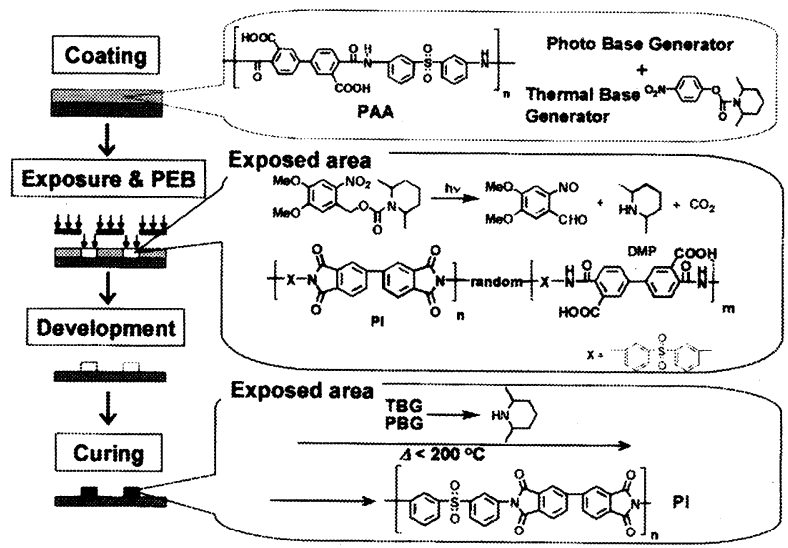

Scheme 1. Patterning process of low temperature curable PSPI.

The formulation of PSPI is very simple, just the addition of DNCDP and NDP to a PAA solution which is prepared from BPDA and SDA in DMAc. The PSPI solution is spin-coated and baked in the usual way. Then, the film is exposed to UV light to produce 2,6dimethylpiperidine from DNCDP. Upon postexposure baking (PEB) treatment of the PSPI film, 2,6-dimethylpiperidine catalyzes the imidization of the PAA. The dissolution rate of the exposed area to TMAHaq decreases and a negative image is formed. The subsequent lowtemperature cyclization of a PAA into a PI pattern proceeds at $200{ }^{\circ} \mathrm{C}$ with 2,6dimethylpiperidine generated from thermal decomposition of NDP. As a consequence, the direct formulation of chemically amplified PSPI simplifies the photolithographic process, and the following thermal treatment at $200{ }^{\circ} \mathrm{C}$ promotes the imidization of the PAA

\section{Experimental}

\subsection{Materials}

DMAc was purified by vacuum distillation. SDA purchased from Tokyo Chemical Industry Co., Ltd. was recrystallized from tetrahydrofuran (THF) under nitrogen. BPDA purchased from Tokyo Chemical Industry Co., Ltd. was dried for $12 \mathrm{~h}$ at $180^{\circ} \mathrm{C}$ in vacuo before use. DNCDP was prepared according to the reported procedure. Other reagents and solvents were obtained commercially and used as received.

\subsection{Synthesis of the PAA (BPDA/SDA)}

BPDA $(0.294 \mathrm{~g}, 1.00 \mathrm{mmol})$ was added to a solution of SDA $(0.248 \mathrm{~g}, 1.00 \mathrm{mmol})$ in DMAc $(3.10 \mathrm{~mL})$. The mixture was stirred at room temperature for $12 \mathrm{~h}$ to give a viscous clear solution. The yield was quantitative. An inherent viscosity of PAA was $0.43 \mathrm{dL} / \mathrm{g}$ at a concentration of $0.5 \mathrm{dL} / \mathrm{g}$ in DMAc at $30^{\circ} \mathrm{C}$.

\subsection{Synthesis of NDP}

A $100 \mathrm{~mL}$ round-bottomed flask equipped with a dropping funnel and a magnetic stirring bar was flushed with nitrogen, charged with dry THF $(30.0 \mathrm{~mL})$ and 2,6-dimethylpiperidine $(2.83 \mathrm{~g}, 25.0 \mathrm{mmol})$, and cooled in an ice-bath. A solution of $p$-nitrophenyl chloroformate (2.01 $\mathrm{g}, 10.0 \mathrm{mmol})$ in dry THF $(10.0 \mathrm{~mL})$ was then added dropwise through the dropping funnel to the flask. After the addition was completed, the solution was stirred for $4 \mathrm{~h}$ at room temperature under nitrogen, and poured into water. The solution was extracted with ethyl acetate $(30 \mathrm{~mL}$ $\times 3$ ), and the organic layer was washed with sodium hydrogen carbonate solution $(50 \mathrm{~mL} \times 2)$, dried over with anhydrous magnesium sulfate, and concentrated under reduced pressure. The residue was recrystallized from hexane/toluene $(5: 1 \mathrm{v} / \mathrm{v})$ to afford a white plate $(1.96 \mathrm{~g}, 71 \%)$. IR (KBr, v . cm $\left.{ }^{-1}\right): 3112(\mathrm{Ar}-\mathrm{H}), 3081$ (Ar-H), 2969 (C-H), 2935 (C-H), 1712 (O-CO-N), 1523 $\left(\mathrm{ArNO}_{2}\right), 1347\left(\mathrm{ArNO}_{2}\right) .{ }^{1} \mathrm{H}$ NMR $(300 \mathrm{MHz}$, $\left.\mathrm{CDCl}_{3}, \sigma \mathrm{ppm}\right): 1.33(\mathrm{~d}, \mathrm{~J}=7.0 \mathrm{~Hz}, 6 \mathrm{H}), 1.51-$ $1.87(\mathrm{~m}, 6 \mathrm{H}), 4.45(\mathrm{~m}, 2 \mathrm{H}), 7.30(\mathrm{~d}, 2 \mathrm{H}), 8.25(\mathrm{~d}$, 2H). $\left.{ }^{13} \mathrm{C} \mathrm{NMR} \mathrm{(300} \mathrm{MHz,} \mathrm{CDCl}_{3}, \sigma, \mathrm{ppm}\right)$ : $13.96,21.36,30.39,47.50,122.73,125.44$, 145.05, 153.16, 157.08. Elemental analysis: Calcd. for $\mathrm{C}_{14} \mathrm{H}_{18} \mathrm{~N}_{2} \mathrm{O}_{4}: \mathrm{C}, 60.42 ; \mathrm{H}, 6.52 ; \mathrm{N}$, 10.07; O, 23.00; Found C, 60.50; H, 6.47; N, 10.02; O, 23.01. 


\subsection{Degree of imidization}

The polymer solution was diluted with DMAc to a concentration of $15 \mathrm{wt} \%$, followed by addition of DNCDP or NDP. The solution was spin-coated on a silicon wafer, baked at $100{ }^{\circ} \mathrm{C}$ for $10 \mathrm{~min}$ in air. The film thickness was about $1.0 \sim 1.2 \mu \mathrm{m}$. Then, the films were baked on a hot-plate at each temperature $\left(110 \sim 200{ }^{\circ} \mathrm{C}\right)$ for $10 \mathrm{~min}$. A reference PI film was prepared by heating at $250{ }^{\circ} \mathrm{C}$ for $0.5 \mathrm{~h}$ and $350{ }^{\circ} \mathrm{C}$ for $1 \mathrm{~h}$. Absorption intensities on a FT-IR spectrum at $1376 \mathrm{~cm}^{-1}\left(\mathrm{~A}_{1376}\right)$ assignable to the $\mathrm{C}-\mathrm{N}$ stretching of the imide group and at $1500 \mathrm{~cm}^{-}$ ${ }^{1}\left(\mathrm{~A}_{1500}\right)$ assignable to the aromatic $\mathrm{C}=\mathrm{C}$ stretching were measured, and the degrees of imidization were determined using the following equation (1)

$$
\begin{aligned}
& \text { Imidization (\%) }= \\
& \frac{\left(A_{1376} / A_{1500(\text { samp) }}-A_{1376} / A_{1500(\text { (init) }}\right)}{\left(A_{1376} / A_{1500 \text { (mid) }}-A_{1376} / A_{1500(\text { (mit) }}\right)} \times 100
\end{aligned}
$$

Subscripts between parentheses following $A_{1376}$ $/ A_{1500}$ in the equation indicate states of the polymer films; e.g. (samp) is the polymer sampled at each heating temperature level $\left(110 \sim 120^{\circ} \mathrm{C}\right)$; (init) is initially prebaked PAA at $100{ }^{\circ} \mathrm{C}$; (imid) is the fully cured at $350{ }^{\circ} \mathrm{C}$ for $1 \mathrm{~h}$ in air.

\subsection{Photosensitivity}

A $1.2 \mu \mathrm{m}$ thick photosensitive polymer film was prepared by a $15 \mathrm{wt} \%$ solid content DMAc solution consisting of PAA (83 wt \%), DNCDP (8.5 wt \%) and NDP (8.5 wt \%), followed by spin-coating on a silicon wafer and then prebaked at $100{ }^{\circ} \mathrm{C}$ for $5 \mathrm{~min}$. This film was exposed to $i$-line using a filtered supper-highpressure mercury lamp, PEB at $170{ }^{\circ} \mathrm{C}$ for $2 \mathrm{~min}$. A development of the exposed film was carried out with the developer of $2.38 \mathrm{wt} \%$ TMAHaq. at $25{ }^{\circ} \mathrm{C}$ for $130 \mathrm{sec}$, rinsed with distilled water, and dried with a drier. The characteristic sensitivity curve was obtained by plotting a normalized film thickness to the exposure dose (unit: $\mathrm{mJ} / \mathrm{cm}^{2}$ ). Image-wise exposure was carried out in a contact-printing mode.

\subsection{Measurements}

The Fourier-transferred (FT-IR) and UV-visible spectra were recorded on a Horiba FT-720, a JASCO V-560 spectrometer, respectively. Viscosity measurements were carried out by using an Ostwald viscometer at $30{ }^{\circ} \mathrm{C}$ in DMAc. Thermogravimetric analysis (TGA) was performed on a Seiko TG/DTA 6300 at a heating rate of $10{ }^{\circ} \mathrm{C} / \mathrm{min}$ under a nitrogen stream. The film thickness on silicon wafer was measured by a Veeco Instrument Dektak ${ }^{3}$ surface profiler. Field emission scanning electron microscopy (SEM) was taken with a Technex Lab Tiny-SEM 1540 with $15 \mathrm{kV}$ accelerating voltage for imaging. $\mathrm{Pt} / \mathrm{Pd}$ was spattered on film in advance of the SEM measurement.

\section{Results and Discussion}

3.1 Synthesis of High Transparency PAA In the aromatic PI and PAA, the absorption wavelength of polymers is determined by the energy band-gap between a dianhydrides and a diamine, which is involved a highest occupied molecular orbital (HOMO) and a lowest unoccupied molecular orbital (LUMO), respectively. Therefore, the PAA with high transparency is obtained from a dianhydride which has small electron affinity and a diamine which has a low ionization potential. Thus, we selected BPDA and SDA as a dianhydride and a diamine, respectively. These compounds have reasonable potential to increase the transparency of the resulting PAA and PI.

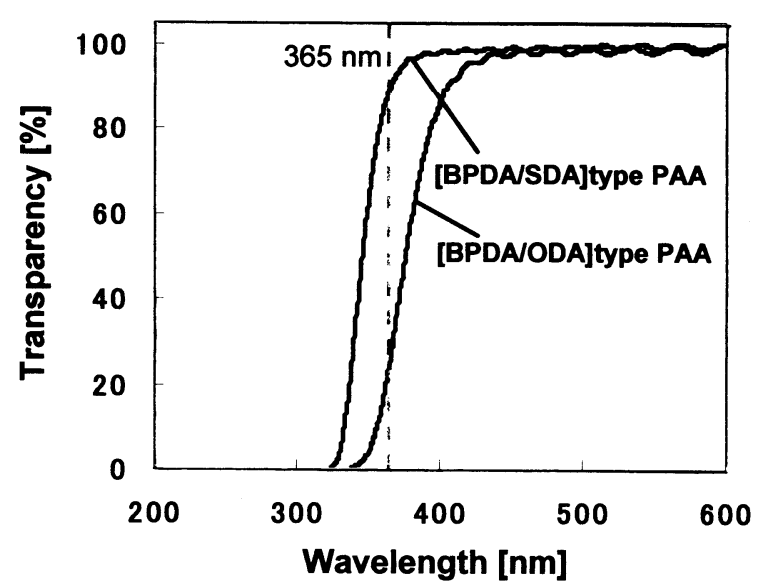

Figure 1. UV-vis spectra of [BPDA/SDA] type PAA (film thickness $2.8 \mu \mathrm{m}$ ) and [BPDA/ ODA] type PAA (film thickness $2.5 \mu \mathrm{m}$ ).

The PAA with an inherent viscosity of 0.43 $\mathrm{dL} / \mathrm{g}$ was prepared from BPDA and SDA. The UV-vis spectra of the PAA film with thickness of $2.8 \mu \mathrm{m}$ is shown in Figure 1 with that of the reference PAA film from BPDA and ODA with thickness of $2.5 \mu \mathrm{m}$. The transmittance of the PAA (BPDA/ODA) film measured at $365 \mathrm{~nm}$ is $89 \%$, which is much higher than that $(26 \%)$ of 
the reference PAA. Thus, the PSPI using the PAA (BPDA/ODA) as a matrix polymer is expected to show a high sensitivity with a 365 $\mathrm{nm}$ light.

\subsection{Synthesis of NDP.}

Although several TBGs have been reported, their thermal stability is not so high. In this PSPI system, a PEB temperature may be high at about $160{ }^{\circ} \mathrm{C}$ because of imidization reaction. Therefore, a new TBG with thermal stability at around $200{ }^{\circ} \mathrm{C}$ should be developed. NDP was designed and synthesized from 2,6-dimethyl piperidine and $p$-nitrophenyl chloroformate. NDP would be decomposed into $p$-nitorophenol and 2,6-dimethylpiperidine by hydrolysis on a carbamate bond. NDP was obtained good yield and indicated high thermal stability $\left(\mathrm{T}_{\mathrm{d} 5 \%}=210\right.$ $\left.{ }^{\circ} \mathrm{C}\right)$.

A degree of imidization (DI) of the PAA film containing $10 \mathrm{wt} \%$ NDP or no TBG up to 200 ${ }^{\circ} \mathrm{C}$ was monitored with FT-IR spectroscopy. The DI in the solid state was calculated from two characteristic absorptions corresponding to the aromatic $\mathrm{C}=\mathrm{C}\left(1500 \mathrm{~cm}^{-1}\right)$ and imide $\mathrm{C}-\mathrm{N}$ stretching $\left(1375 \mathrm{~cm}^{-1}\right)$ as compared with thermally imidized PI (cured at $350{ }^{\circ} \mathrm{C}$ for $1 \mathrm{~h}$ ). The effect of NDP loading in the PAA film and the influence of temperature on the DI was investigated (Fig. 2).

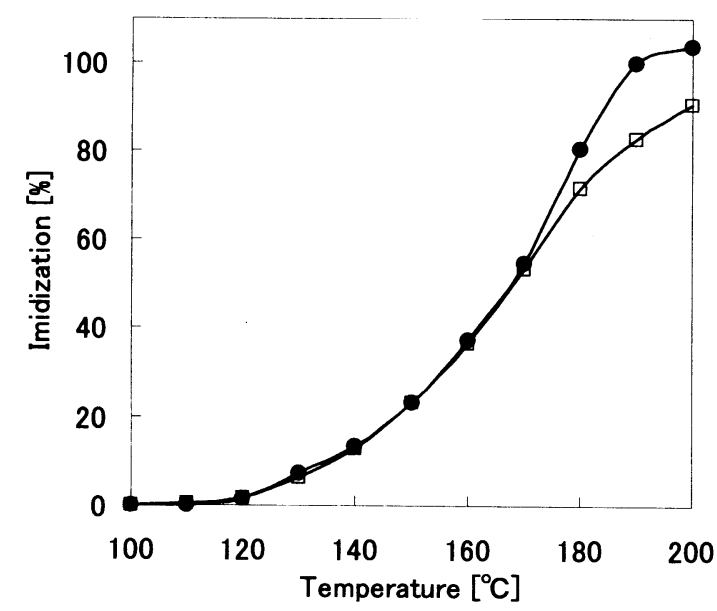

Figure 2. The DI of the PAA film with NDP (•) with $10 \mathrm{wt} \%$ additive for PAA and no additivefree (口).

The DI of PAA films containing NDP is accelerated at around $180{ }^{\circ} \mathrm{C}$, which is corresponding to the decomposition temperature of NDP, and reached $100 \%$ at $200{ }^{\circ} \mathrm{C}$. On the other hand, the DI of the TBG-free PAA film is
$85 \%$ of imidization at $200{ }^{\circ} \mathrm{C}$. These results clearly indicate that NDP acts as a TBG.

3.3 Lithographic Evaluation

To obtain contrasting pattern profiles from exposed and unexposed areas, the effect of PEB temperature, PEB time, and exposure dose were investigated. The Films were obtained by spincasting the diluted polymerization solution of the PAA containing DNCDP (8.5 wt \%) and NDP (8.5 wt \%) on a silicon wafer, and then prebaking at $100{ }^{\circ} \mathrm{C}$ for $5 \mathrm{~min}$ in air. This photosensitive polymer film was irradiated with UV light at $365 \mathrm{~nm}$ ( $i$-line) using a filtered superhigh-pressure mercury lamp, PEB at a set temperature, and developed with TMAHaq at 25 ${ }^{\circ} \mathrm{C}$.

To clarify the difference of dissolution behavior between the exposed and unexposed areas, the effect of the PEB temperature and the PEB time was studied by measuring the film thickness after development. The dissolution rates were estimated by the change in film thickness before and after development.

First, the effect of the PEB temperature on the dissolution rate was investigated and the results are shown in Figure 3. Although the dissolution rate of both in the exposed and unexposed areas decreases with increasing the PEB temperature, the highest dissolution contrast is obtained at $170^{\circ} \mathrm{C}$, where the PEB time and exposure dose are for $2 \mathrm{~min}$ and $500 \mathrm{~mJ} / \mathrm{cm}^{2}$, respectively.

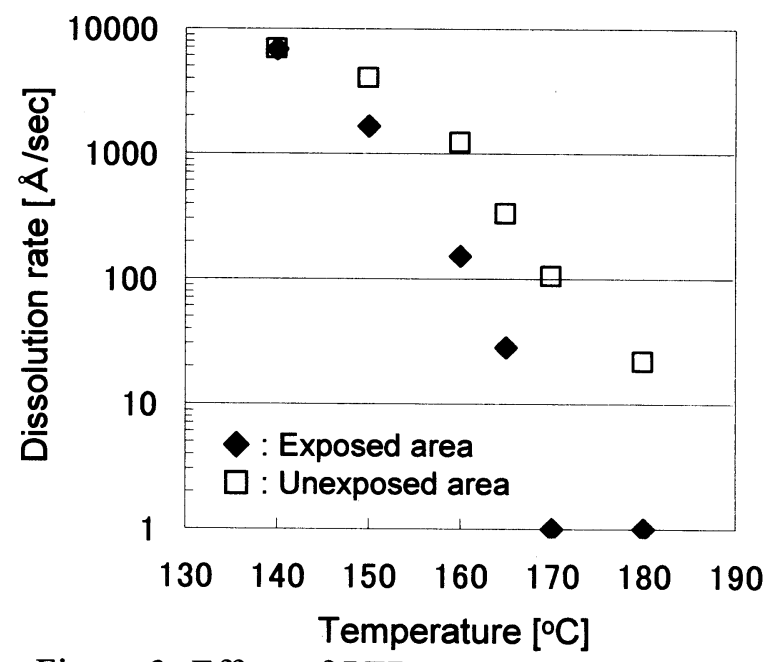

Figure 3. Effect of PEB temperature to PAA on the dissolution rate for the PAA/DNCDP/NDP $(83 / 8.5 / 8.5 \mathrm{wt} / \mathrm{wt} / \mathrm{wt})$ resist system in exposed $(\diamond)$ and unexposed area (). The pre-bake, the $i$ line exposure and PEB time were fixed as 100 ${ }^{\circ} \mathrm{C}$ for $5 \mathrm{~min}, 500 \mathrm{~mJ} / \mathrm{cm}^{2}$ and for $5 \mathrm{~min}$, respectively. 
The effect of PEB time is summarized in Figure 4. The PEB times are changed from 1 to 5 min where the PEB temperature and exposure dose are fixed at $170{ }^{\circ} \mathrm{C}$ and $500 \mathrm{~mJ} / \mathrm{cm}^{2}$, respectively. The dissolution rate becomes almost zero at $170{ }^{\circ} \mathrm{C}$ for $2 \mathrm{~min}$ and the highest dissolution contrast is obtained. Thus, the PEB temperature and time are critical to lithographic evaluation in this PSPI.

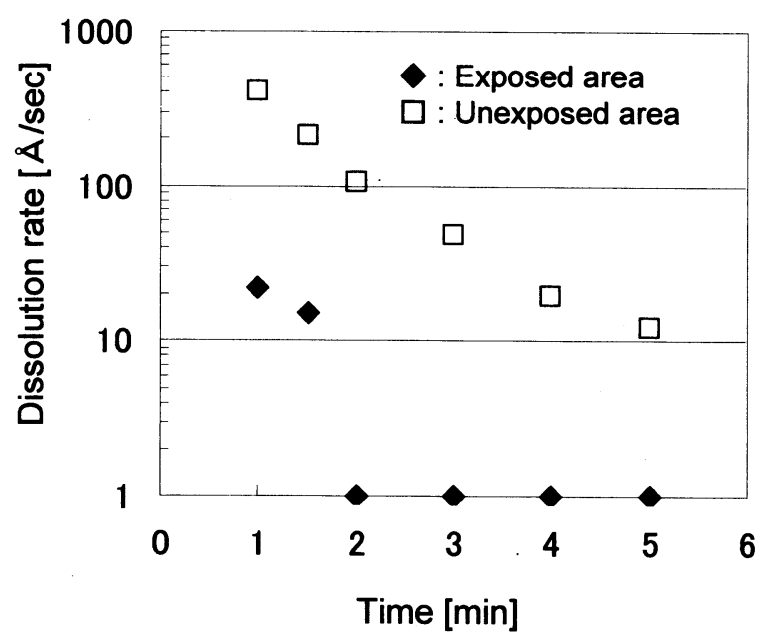

Figure 4. Effect of PEB time to PAA on the dissolution rate for the PAA/DNCDP/NDP $(83 / 8.5 / 8.5 \mathrm{wt} / \mathrm{wt} / \mathrm{wt})$ resist system in exposed $(\diamond)$ and unexposed area ( $\square$ ). The pre-bake, the $i$ line exposure and PEB temperature were fixed as $100{ }^{\circ} \mathrm{C}$ for $5 \mathrm{~min}, 500 \mathrm{~mJ} / \mathrm{cm}^{2}$ and at $170{ }^{\circ} \mathrm{C}$, respectively.

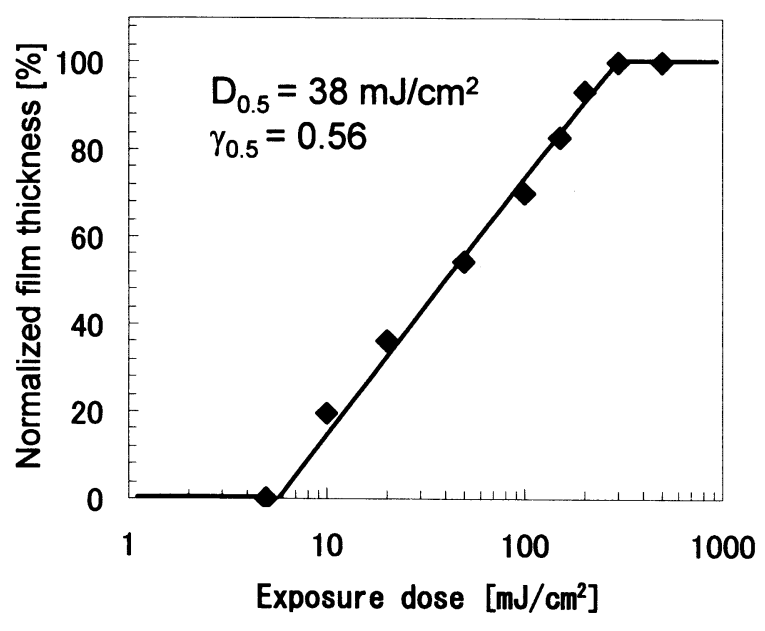

Figure 5. Characteristic photosensitive curve for the PAA/DNCDP/NDP (83/8.5/8.5 wt/wt/wt) resist system in $1.2 \mu \mathrm{m}$ film thickness. The prebake and PEB were fixed as $100{ }^{\circ} \mathrm{C}$ for $5 \mathrm{~min}$ and at $170{ }^{\circ} \mathrm{C}$ for $2 \mathrm{~min}$, respectively.
Based on these preliminary optimization studies, a photosensitive polymer consisting of PAA (83 wt \%), DNCDP (15 wt \%) and NDP (8.5 wt \%) was formulated. The photosensitivity curve of a film $1.2 \mu \mathrm{m}$ thick is shown in Figure 5 (PEB treatment was conducted at $170{ }^{\circ} \mathrm{C}$ for $2 \mathrm{~min}$ and developed with $2.38 \mathrm{wt} \%$ TMAHaq.). This resist system reveals the photosensitivity $\left(D_{0.5}\right)$ of $38 \mathrm{~mJ} / \mathrm{cm}^{2}$ and the contrast $\left(\gamma_{0.5}\right)$ of 0.56 with $i$-line exposure. This PSPI has high sensitivity but its contrast is low compared to that of the PSPI (BPDA/ODA). The high sensitivity is attributed to the high transparency of the PAA.

\subsection{Low Temperature Imidization of PSPI}

To investigate the imidization of PSPI using FT-IR spectroscopy, the PAA film containing DNCDP (8.5 wt \%) and NDP (8.5 wt \%) was baked on a hotplate at designated temperatures, such as a pre-bake at $100^{\circ} \mathrm{C}$ for $10 \mathrm{~min}, \mathrm{PEB}$ at each temperature $\left(110 \sim 200{ }^{\circ} \mathrm{C}\right)$ for $10 \mathrm{~min}$ after exposure $\left(500 \mathrm{~mJ} / \mathrm{cm}^{2}\right.$ of $i$-line). A reference PI film was prepared by the following thermal treatment, such as at $250{ }^{\circ} \mathrm{C}$ for $0.5 \mathrm{hr}$ and 350 ${ }^{\circ} \mathrm{C}$ for $1 \mathrm{~h}$ in air.

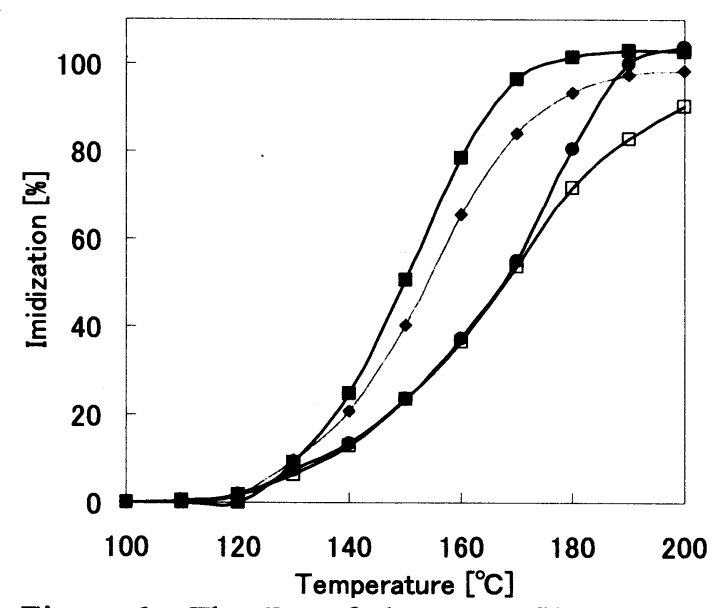

Figure 6. The DI of the PAA film containing DNCDP (8.5 wt \%) and NDP (8.5 wt \%) (घ), only DNCDP (10 wt \%) (४), only NDP (10 wt \%) (•), and no additive ( $\square)$.

Figure 6 shows that the imidization starts from $130{ }^{\circ} \mathrm{C}$, and completely finishes until $200{ }^{\circ} \mathrm{C}$ because of influence of the base from DNCDP. It is interesting that the DI of the PAA film containing DNCDP (10 wt \%) which was also exposed at $500 \mathrm{~mJ} / \mathrm{cm}^{2}$ of $i$-line is lower than that of the PAA film containing DNCDP and NDP. Moreover, the DI of the PAA film containing only NDP (10 wt \%) is $80 \%$ at around $180{ }^{\circ} \mathrm{C}$. It indicates that hydrolysis of NDP is accelerated by the base from DNCDP. 
These films were baked on the condition of lithographic evaluation. The DIs of the PAA films containing DNCDP (8.5 wt \%) and NDP (8.5 wt \%), only DNCDP (10 wt \%), only NDP (10 wt \%), and no additive are 100, 91, 80, and $71 \%$, respectively at $180{ }^{\circ} \mathrm{C}$. Thus, the effect of NDP on the DI is around $10 \%$.

\subsection{Image formation of PSPI}

Figure 7 presents a scanning electron micrograph of a contact-printed image obtained with the aforementioned system: the resist was exposed to $500 \mathrm{~mJ} / \mathrm{cm}^{2}$, post baked at $170{ }^{\circ} \mathrm{C}$ for 2 min, and developed with 2.38 wt \% TMAHaq.

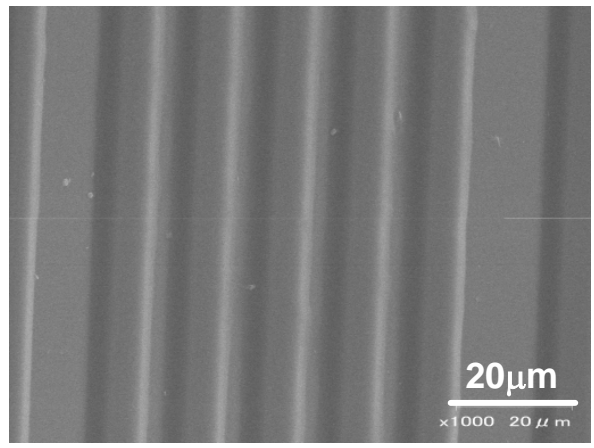

Figure 7. SEM image of negattive-pattern of $2.0 \mu$ m-thick film based on PAA/DNCDP/ NDP (83/8.5/8.5 wt/wt/wt). The pre-bake, the $i$-line exposure and PEB were fixed as $100{ }^{\circ} \mathrm{C}$ for 5 $\mathrm{min}, 500 \mathrm{~mJ} / \mathrm{cm}^{2}$ and at $170{ }^{\circ} \mathrm{C}$ for $2 \mathrm{~min}$, respectively.

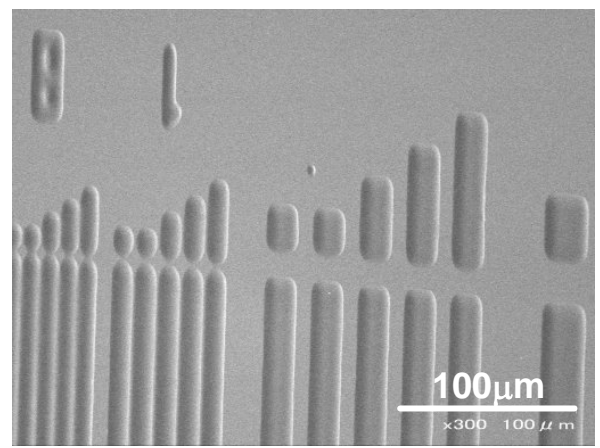

Figure 8. SEM image of PI pattern cured at 200 ${ }^{\circ} \mathrm{C}$ for $1 \mathrm{~h}$.

A clear, negative PAA pattern with an $8 \mu \mathrm{m}$ feature can be observed when a $2.0 \mu \mathrm{m}$ thick film was used. The printed pattern was converted to the PI pattern without deformation by heating at elevated temperature up to $200{ }^{\circ} \mathrm{C}$ for $1 \mathrm{~h}$ in air (Figure 8). The film thickness decreased to $1.8 \mu \mathrm{m}$ due to the evaporation of water, amine, and phenol which were byproducts and the solvent.

\section{Conclusions}

A negative-type PSPI based on the PAA solution, PBG, and TBG was developed. The photosensitivity and contrast of $1.2 \mu \mathrm{m}$ thick resist film consisting of PAA (83 wt \%), DNCDP (8.5 wt \%), and NDP (8.5 wt \%) were $38 \mathrm{~mJ} / \mathrm{cm}^{2}$ and 0.56 , respectively and this PSPI produced a clear negative-tone image with $8-\mu \mathrm{m}$ features. This pattern was converted subsequently into the corresponding PI upon heating at $200{ }^{\circ} \mathrm{C}$. In addition, NDP indicated a weak effect of base amplification. This new patterning process using a hydrolysis type TBG potentially provide a more efficient and versatile patterning process for PSPIs compared to the standard route that requires the modification of PAAs and high imidization temperatures.

\section{References}

1. R. Rubner, H. Ahne, E. Kühn and G. Koloddieg, Photogr. Sci. Eng., 23, 303 (1979).

2. Y. Matsuoka, K. Yokota, S. Ogitani, A. Ikeda, H. Takahashi and H. Ai, Polym. Eng. Sci., 32, 1618 (1992).

3. N. Yoda and H. Hiramoto, J. Macromol. Sci., Chem., A21, 1641 (1984).

4. A. Zhang, X.Li, C. Nah, K. Hwang and M. H. Lee, J. Polym. Sci., Part A: Polym. Chem., 41, 22 (2003).

5. M. Ueda and T. Nakayama, Macromolecules, 29, 6427 (1996).

6. Y. Watanabe, K. Fukukawa, Y. Shibasaki, and M. Ueda, J. Polym. Sc: Part A. Polym. Chem., 43, 593 (2005).

7. K. Fukukawa, Y. Shibasaki, and M. Ueda, Polym. Adv. Technol. 17,131-136 (2006).

8. K. Fukukawa, T.Ogura, Y. Shibasaki and M. Ueda, Chem. Lett, 34, 1372 (2005). 